\title{
CARVALHO CALERO NARRADOR. SCÓRPIO E AS MULLERES
}

CARVALHO CALERO AS NARRATOR. SCÓRPIO AND WOMEN

\section{Henrique Rabuñal IES Ramón Menéndez Pidal (A Coruña)}

\begin{abstract}
Resumo: Neste traballo faise un repaso á produción narrativa de Carvalho Calero constituída por nove pezas literarias. Faise unha clasificación abordando as crónicas e a narrativa infantil e tamén textos tan emblemáticos como Aos amores seródios. Facemos tamén unha aproximación á celebrada obra Scórpio deténdonos nas múltiples e diversas relacións que o protagonista da narración mantén con varias mulleres.
\end{abstract}

\begin{abstract}
This work reviews the narrative production of Carvalho Calero that comprises nine literary pieces. A classification is provided by addressing the author's chronicles and children's fiction and also such emblematic texts as Aos amores seródios [Late Loves]. His celebrated work Scórpio [Scorpio] is also analysed, with a focus on the multiple and diverse relations in which the protagonist engages with several women.
\end{abstract}

Palabras chave: Ricardo Carvalho Calero, narrativa, crónicas, narrativa infantil, Scórpio, mulleres.

Key words: Ricardo Carvalho Calero, narrative, chronicles, children's narrative, Scórpio, women.

\section{CARVALHO CALERO NARRADOR}

Quero comezar a miña intervención nesta actividade agradecendo á Real Academia Galega a oportunidade que se nos brinda de volver máis unha vez ${ }^{1}$ ao mundo literario de Carvalho Calero. E síntome moi feliz de facelo acompañando ás ilustres

1 Referímonos aos nosos traballos (Rabuñal 2000, 2011 e 2020). 
amigas Pilar Pallarés e Laura Tato, cuxos traballos contribuíron a pór no mapa literario e intelectual do noso século XX a inmensa figura de don Ricardo.

Afortunadamente hoxe contamos con numerosas e valiosas achegas a todas as dimensións de Carvalho como home e escritor, tamén á súa narrativa e moi especialmente a Scórpio, obra que por moderna e orixinal atraeu o interese de moitas persoas lectoras e estudosas das nosas letras. Estamos seguros de que estas xornadas de estudo da figura e da obra de Carvalho constituirán outro elemento determinante para situar o noso escritor no lugar de honra que lle corresponde.

Na súa produción narrativa hai unha primeira etapa nos anos 40 e 50 que abrangue os títulos A gente da Barreira (GB), Os señores da Pena (SP), O lar de Clara (LC), As pitas baixo a choiva (PC), Os tumbos (T) e A cegoña (C), isto é, seis das súas nove obras. Foron anos duros para un escritor represaliado pola ditadura pero que considera un labor patriótico e unha necesidade persoal indagar na súa propia peripecia biográfica como acontece nos textos de protagonista infantil (LC, PC, T e C) e na historia das sagas que nos brindan GB e SP. Estes textos, moitas veces publicados en revistas, coñecen poucas edicións e probabelmente pouca difusión, agás GB (que se publica en 1951, 1982, 1984, 1997, 2002 e 2020) e Scórpio (S) editado por Sotelo Blanco (1987, 1989, 1990 e 1993), a AS-PG (1997) e Através Editora (2017).

O volume que contén a súa Narrativa completa non pasou da primeira edición. Dese conxunto de pezas temos que illar Aos amores seródios (AS), publicado nunha revista en 1979 e logo inserido en 1984 na Narrativa completa. En 1985 don Ricardo deu a coñecer en Agália baixo o pseudónimo de Namiq Ziyá o texto Provérbios otomanos: de Selim a Solimám (SS). Esta etapa final correspóndese co momento en que o profesor deixou a docencia universitaria aproveitando a oportunidade para recompilar moitas das súas obras e ofrecernos como agasallo final a memorábel Scórpio. Fique clara tamén a preferencia do noso autor polas formas narrativas breves: contos (como PC, T, C, AS ou SS), novelas (como LC e SP) ou suma de relatos (como GB). O romance propiamente dito cultivarao en Scórpio.

\subsection{As CRÓNICAS}

Dentro desta epígrafe ${ }^{2}$ faremos un breve achegamento aos seus títulos GB e SP.

A gente da Barreira, escrita nos anos 40 e publicada en 1951, fora premiada un ano antes pola Editorial dos Bibliófilos Gallegos e ten o mérito de ser a primeira novela

2 Todas as referencias aos textos están tomadas do volume de Carvalho Calero A Gente da Barreira e outras histórias (1982), agás SP e LC para os que usamos Narrativa completa (1984). SS só foi publicado en Agália (1985). De Scórpio usamos a edición da AS-PG (1997). 
publicada en galego en Galiza despois da guerra, inscrita na tentativa de reconstruír a nosa literatura e de repensar os problemas colectivos e nacionais do país.

GB propón unha excursión polo século XIX galego captando aspectos da súa vida rural, da decadencia da fidalguía, anunciando a chegada do sistema económico moderno adubado de novas profesións e de novas clases. $\mathrm{O}$ autor declara terse informado dun universo ao que era alleo por membros desas familias nos anos posteriores á guerra. $\bigcirc$ relato ofrécese como unha suma de dezanove capítulos ao xeito practicado por Castelao en Os dous de sempre. O narrador nega a posibilidade dos diálogos e pretende exercer de cronista e de testemuña dun mundo no que comparece o carlismo, os abusos da fidalguía, a división entre os señores e os criados, a emigración ou o maragato comerciante. A saga dos Frade de Eirís, a sorte da casa emblemática da Barreira e a súa contorna xeográfica, social e económica liga entre si os capítulos que un narrador en terceira persoa resolve con rapidez.

A narración vainos contando a historia dos Frade de Eirís e dos seus sucesivos señores: Ramón Frade e Tereija Abraira das Torres, Armando e Mercedes Portela, Álvaro e Amelia Ameixeiras, Andrés e Emilia de Camporredondo.

Ramón Frade é quen constrúe a casa farta da Barreira casando coa rapaza do Pazo de Gomesende, dona Tereija. A criada neste tempo é Ludivina. $O$ tratante de gando fixera unha casa para que nela fose feliz "na entraña da esgrevieza montesía" a súa muller "nobre, formosa e lanzal". O señor da Barreira ten que defenderse da partida carlista que lidera o abade don Joán Martelo. $\bigcirc$ marido de Ludivina, o Breixo, en primeira instancia integrado na carlistada e logo traballador da Barreira, será aforcado para que pague así a súa traizón. Don Ramón fixéralles unha casiña aos criados. En morrendo o Breixo nacía a súa filla Tereijiña xusto cando a señora da Barreira daba tamén a luz a súa filla. Tereijiña, criada na Barreira, irá substituíndo a súa nai e terá unha filla, Vertudes, co novo señor da Barreira, Armando.

O señor da Barreira ten tres fillos varóns (Armando, o morgado, Enrique, o avogado, e José Manuel, o tratante) e unha filla, Rosario, a que máis se ocupa da casa. Morren os señores da Barreira e tamén Tereijiña, nai de Vertudes, a nova criada da señorita Rosario, e despois nai de Sabeliña, abandonada polo seu pai.

Don Armando, o novo señor da Barreira, logo de múltiples aventuras con mozas da terra, casa con Mercedes Portela, a nova señora, axudada pola súa cuñada e a Vertudes. Serán ademais os pais do futuro señor da Barreira: Álvaro, no seu día casado con Amelia Ameixeiras. Ao morrer Armando, o seu irmán José Manuel casa coa cuñada Mercedes. Continúan as partidas carlistas que supoñen mesmo a detención de José Manuel. Os novos señores da Barreira teñen tres fillos: Andrés, avogado, Rosariño, casada con Andrés Cheda, fillo de comerciantes, e 
Ramón. Álvaro, o morgado, é obrigado polo seu tío a estudar en Lucenza cos escolapios antes de facerse forte na gobernanza da súa casa. Logo, ao cumprir os dezasete anos, casa con Amelia Ameixeiras, filla única dun procurador. Os novos señores da Barreira provocan a saída dos anteriores para outra casa. Vertudes axuda á nova señora.

A celebración da misa é un escenario no que todo está regulado: dous bancos de castiro para acomodar os Frades escindidos en dúas casas, os fidalgos ocupaban o banco máis próximo ao altar, no segundo banco figuraban as mulleres da servidume. As mortes sucédense: a de José Manuel primeiro, despois a do seu fillo Ramón de tuberculose. Mentres, Rosariño, filla de José Manuel e Mercedes, casa cun fillo de comerciantes que non acabara ningunha carreira: Andrés Cheda. A moza casará espida de dote e non asistida pola súa familia. O seu irmán Andrés exerce de avogado e soña con triunfar na política como fixeran outros devanceiros seus.

Outras figuras van tomando relevancia: Pedro o maragato, solitario e avaro, que gaña moitos cartos co viño, o sal, o trigo ou o pemento e que vive na casa da Graña que don Ramón Frade arranxara para Ludivina e o seu home. O Rosende que tenta saír da miseria, un emigrante tísico, ou Antón das Cabras que, aproveitándose da necesidade de cartos de don Álvaro, logra comprarlle a Graña.

Pasada a restauración, a familia dos Frade de Eirís esmorece mentres nace un novo tempo. Os pazos esborrállanse irremediabelmente. A Barreira está fechada nos invernos. Álvaro vende parte do seu patrimonio, a súa familia busca emprego nas vilas. Morre dona Mercedes. Rosariño ten moitos fillos e os negocios do seu marido marchan mal. Morre Álvaro Frade Portela. A súa viúva Amelia está acompañada de Vertudes. Don Armando non ten netos en terras da Barreira. Uns exercen as súas carreiras en Souto, a capital provincial, outros montan os seus negocios. Agora é a caste de Rosende a que provoca que se lles incline todo o mundo. Sabeliña, filla de Vertudes, militante inimiga da caste emerxente que simboliza Rosende, sente unha dor acompañada de bágoas cando conclúe a narración.

Os señores da Pena supón unha maior contención temporal, unha notábel redución de figuras e a permanencia dun narrador omnisciente que en terceira persoa executa outra crónica en certa medida próxima a GB. En SP, escrita nos mesmos anos que GB e publicada por vez primeira en 1984 (Narrativa completa), o autor volve ao universo rural, fidalgo e labrego. $\mathrm{O}$ texto aparece organizado en dezaseis capítulos, prólogo e epílogo, o primeiro e o derradeiro. O relato principia cunha poética descrición da paz rural dominical posuída pola figura do señor Valentín, alto e groso, cano e barbado. Tamén aquí a casa é "grande, forte, séria" (1984, p. 
111). Cruza unhas palabras co médico Robustiano cando este se encamiña a axudar a parir á filla do ferreiro das Pías.

A casa de don Valentín e da súa curmá e esposa dona Leonor é das mellores da comarca. Teñen catro fillos. Un, metido nunha parroquia afastada, non vén pola casa. Dous casados viven de traballos facilitados por un tío. A filla Vicentiña medrara cos tíos en Madrid e mesmo estudara unha carreira, pero pasa os días fechada no seu cuarto. Acoden caseiros e labregos. Cando toca facer testamento, os señores da Pena pretenden que non se desfaga o conseguido. A casa e as terras serán para o fillo crego. Os outros varóns quedan tamén con propiedades e para a filla a súa correspondente lexítima.

Morre don Valentín pero a casa segue medrando "como a escuma". Vicenta non volve saír do seu cuarto. $\bigcirc$ fillo crego, don Bieito, toma as rendas. Morre dona Leonor. $O$ tío cura dispón faena para todos os sobriños. Morre o fillo Antonio deixando viúva e seis fillos. Ermitas, sobriña do cura, faise a muller da casa. $\mathrm{O}$ crego reparte o testamento entre os herdeiros buscando sempre quen poida conservar a facenda.

Daniel é fillo dun labrador forte que traballaba na Pena. Convértese no brazo dereito de don Bieito. Un día don Bieito convoca o neto máis vello de don Valentín. Para el será a casa. O resto é para os demais herdeiros a partes iguais. Pero Daniel bota de contas se casar con Ermitas e ter un fillo para herdalo todo.

Coincidindo coa doenza e o inminente pasamento de don Bieito, Daniel e Ermitas chaman con urxencia un notario para que o crego lle faga a mellora a Ermitas e decontado anuncian o seu casamento. $O$ novo señor da Pena, Daniel, aparece no último capítulo gobernando a elección de alcalde, recibindo caseiros e tamén, coas pernas estalicadas, a caricia da araxe na solaina.

\subsection{NARRATIVA INFANTIL}

A infancia está presente en catro obras de don Ricardo: T, PC, C e LC. Faremos unha breve aproximación aos catro textos.

Os tumbos, publicado en 1950 na revista Alba, condúcenos a esa casa de veraneo con horta e merlo, con coellos e galiñas, con caza de grilos e moscas na que o narrador pasou momentos memorábeis da súa nenez. É un caso de analepse ben querido polo autor, moitas veces levado a este movemento temporal retrospectivo destinado a relatar episodios da súa infancia vividos no seo da súa familia -sempre tan relevante. Era a casa dos trasnos vividos por un cativo que aínda non chegara ao decenio. A anécdota cóntanos como nas noites daquela casa se ouvían tumbos e como a neneira cría ver un fantasma na súa alcoba. Tamén como un consumeiro era alcanzado por misteriosas mazás voadoras. Coa benemérita presente, a 
cociñeira confesa o seu pecado de amor: un mozo mariñeiro na cidade á que ela pretende volver decontado. $\mathrm{O}$ dos tumbos e o das mazás foran cousa súa, pecado que deberá pagar co seu despedimento pero tamén coa complicidade comprensiva e certa simpatía do narrador, que lembra este episodio da súa nenez cando xa é un home. Pero, no momento de aconteceren estes feitos, o noso analepsista quere ser militar e le El dos de mayo de López García.

As pitas baixo a choiva publicouse en 1952 en Lar. En PC volvemos ao universo de T a través doutra analepse. Tamén emerxe a vida familiar. $\mathrm{O}$ narrador evoca aquí capítulos da súa biografía estival: os galos e as galiñas daquela casa venerada da nenez e o lecer no que cultivou o amor polos animais. Un narrador que lembra o curro das galiñas bautizadas por el mesmo. Tamén a chuvia estival e como o raparigo non para até meter na casa as pitas e o galo, axudado pola familia, antes de pórse a cuberto cando xa estaban todos mollados.

A cegoña apareceu en 1957 en Vida gallega. Parte o autor dunha historia acontecida a unha súa profesora de alemán, polo que o mundo rural do conto non é de ambientación galega. En $\mathrm{C}$ verificamos da man dun narrador omnisciente en terceira persoa o drama que poden causar os enganos tradicionais de que son obxecto as crianzas. Estamos nun escenario que non é o da nenez do autor. É o país de Erika, o das altas penas, o vento, a montaña, a avea, o centeo, as cegoñas, os miñatos, o río, os galos e a súa granxa. Esta cativa de sete anos non ten con quen xogar e quere facelo con outra nena nun país no que os nenos son traídos polas cegoñas.

Os meniños fican durmidos no fondo do río onde os colle a cegoña. Pódese pedir neno ou nena pondo dous ou tres terróns de azucre a carón dos vidros da xanela. Erika decididamente quere unha irmá, pois xa ten irmáns varóns, e de madrugada leva o neno (Hans) que acaba de ter a súa nai ao río. Olla como o río o leva. Volve á casa e repón esperanzada os tres terróns para que non se confunda a cegoña. E dorme feliz, convencida de que a cegoña vai rectificar traéndolle a irmanciña desexada. Hans, froito daquel erro, irá a outra granxa.

En O lar de Clara don Ricardo recoñece que se trata de:

páginas escritas para loitar contra a destrutora hostilidade dun tempo baleiro e adverso que había que encher e conjurar coa actividade que nos defende de nós mesmos e do mundo circunstante (1984, p. 11). 
Vincula este relato con PC, T e C. O texto evoca, a través de varias analepses, a infancia do narrador en Ferrol e ilustra a existencia da súa familia; a súa propia e íntima saga.

En LC o material narrativo, máis extenso, distribúese en dezasete breves capítulos. Desde o primeiro adiviñamos a infancia ferrolá do autor. A vila mariñeira de tabernas e rúas estreitas, o despotismo ilustrado e as rúas a xeito de taboleiro de xadrez, o murallón que agocha os estaleiros, os arsenais e os tres peiraos. Os técnicos ingleses coa súa capela evanxélica. Os vistosos desfiles militares. As selleiras e os coches de cabalos.

O narrador sitúase aos corenta anos da súa vida na casa natal que daba á Praza Vella, coa súa feira mensual. E avisa ao narratario - moi determinante nesta narración- de que pasaron moitos anos e de que as súas lembranzas non son nítidas nin grandes. "Pouco lembro de min mesmo" (Carvalho 1984, p. 158). Evoca o cinema e como foi ofrecido a Santa Lucía por unha doenza ocular e á Virxe do Carme por un accidente no mar. $\mathrm{O}$ que lembra o narrador da súa infancia cóntao pero non se define como escritor, ignora a existencia de lectores, dubida se publicará estas lembranzas.

É un comerciante coma seu pai pero que cursou o bacharelato e que fixo a súa fortuna en Cuba. Ao marchar a Cuba tiña dúas irmás, Maruja e Clara, e un irmán, Ramón, morto na guerra civil. Clara, casada e con catro fillos, é a dona da casa en que vive o narrador. En Vigo ten previsto embarcar para a Habana. Escribe para si e porque si. Corenta anos despois de nacer, a cidade xa coñece o tranvía e o automóbil, e a casa de Clara está no extremo oposto da casa natal. A xente teno por rico. Evoca a figura dos pais: el comerciante, viaxante, empresario, consignatario de buques, apoderado dunha casa de banca. Tamén a primeira escola co irmán Duarte. Aquel neno estaba sabido da existencia da morte.

Lembra os seus catro irmáns: Duarte, dúas nenas e Rafael. Os pais tiñan unha boa posición. E a terríbel morte de Rafael. O verán pasábano na aldea nunha casa alugada preto da cidade. Nunha boa casa. Lembra a primeira guerra mundial e a asistencia ao cinema. E a casa estival alugada á beira do mar á que se despraza a familia en coche de cabalos. A epidemia de gripe lévalle a nai.

Viven co narrador e os seus irmáns a avoa (viúva dun militar) e a madriña (viúva dun suicida moito máis vello ca ela e vítima dunha doenza incurábel). $\mathrm{O}$ pai e a madriña casan. Duarte padece unha desviación da columna vertebral que lle acaba custando a vida. Clara é a irmá preferida: feliz, agarimosa, intelixente. Maruja era unha nena calada, pouco algareira. Ramón, un pequeno tirano. $\mathrm{O}$ narrador, primoxénito, quería ser xeneral. A casa era rica. Ía para bacharel cando o narrador ía ter un novo irmán: finalmente unha nena morta. Tamén morre a súa madriña. 
Escribe, tense por escritor frustrado, para "botar contas, hai que facer balanzo" (1984, p.187). Os últimos anos da súa nenez son de bágoas e de morte. Ao morrer a súa madriña o pai perde a ilusión de vivir. A economía reséntese. O pai e a súa avoa xa non se levan ben. Unha noite quéimase a casa e esta xa non dispuña de seguro. Logo morre o pai e o narrador vive coa súa avoa até a morte desta. Os seus irmáns refúxianse en casa de parentes. Aos 16 anos vai a Cuba cabo dun familiar. Lembra o exame de ingreso no instituto desde a alcoba da casa de Clara onde escribe e rememora.

O narrador vai embarcar e xa dubida para que seguir escribindo. Clara ten un lar feliz, un marido mestre de escola e o narrador pensa que non se van volver ver. Por que ir a Cuba? Os fillos e o lar de Clara lémbranlle a súa casa de neno, a súa familia e os seus propios irmáns. Ao final decide ficar aquí e non ir a Cuba. Pensa nos fillos de Clara e en axudarlles economicamente. Exercerá de cronista da casta: "é tempo de lecer" (1984, p. 195).

\subsection{A AMÁLGAMA DOS AMORES SERODIOS}

Aos amores seródios é unha obra complexa, mesta e heteroxénea. Dotada intencionadamente dunha anómala estrutura, con múltiples narradores e coordenadas espaciais e temporais e con non poucas intertextualidades das literaturas galega, portuguesa e alemá; nutrida ademais da propia obra dual de creación e de erudición do noso autor e constituída xenericamente como unha abordaxe do mito de Abisag ou como unha toma de postura perante un dos textos que Carvalho mellor coñecía: Os vellos de Castelao. Por non falarmos dos destinatarios textuais e a imbricación do propio autor no elenco destes. Permitídeme unha breve excursión polas sete partes en que se nos ofrece o material narrativo.

1. "Os vellos non deben namorar-se". Este capítulo inicial é un pequeno ensaio que ten como pano de fondo a obra e a tese de Castelao. Unha dialéctica entre a probabilidade e a obriga. Sobre o amor e a vellez. Con afirmacións e preguntas moi suxestivas: o amor novo mata o vello. Que acontece se un vello casado se namora dunha moza casada? Hai moitos vellos que se namoran na historia da humanidade e na historia das nosas letras. Velaí, dinos o autor-ensaísta, o caso contido en $O$ derradeiro amore de Aurelio Ribalta, no que o señor Antón atura en silencio os acoros do seu corazón. Si, en efecto estamos nalgunha das súas intricadas variantes, no caso de Abisag. Pero lembremos que a bela e moza doncela bíblica do Libro dos Reis non foi quen de avivar o desexo do vello rei David. O ensaísta conclúe: o home que agarda a morte ama a vida. Por iso lle parece natural que os vellos se namoren; tanto como que non sexan correspondidos. 
2. "Ásia menor". O salto a respecto desta segunda parte é verdadeiramente espectacular. Uns arqueólogos localizan un santuario por onde serpentea o Meandro, e nel unha cabeza feminina de mármore, que se vai converter nun dos elementos recorrentes da narración. A cabeza resulta máis realista do que idealista e posúe moito carácter. Na súa caluga reza a inscrición que lle dá título ao conxunto: "Aos amores seródios".

3. "O poeta". Non menos inquietante resulta esta terceira parte, integramente constituída polo poema que inspirara, xa de noite á hora da cea e no hotel, a cabeza de mármore a Erik; poema que, asinado polo propio Carvalho Calero, figura co título de "Cabeza de deusa" no seu Futuro condicional, ademais de lembrarmos que Erik Larsson é un dos pseudónimos de don Ricardo. No poema fala Euríloco, fillo de Anaxímenes, escultor de mármore no obradoiro de Euríbio, quen proxecta máis adiante facer o busto e logo na súa madurez o corpo enteiro da imaxe da deusa decapitada.

4. "Consideracións críticas". Recuperamos outra vez o talante do primeiro capítulo, tal como suxire o título. Un ensaio sobre o poema de Erik e tamén sobre a emblemática inscrición. O autor da cabeza non era un mozo, era un vello, un grande artista descoñecido na declinación da súa vida. Un artista que realiza a cabeza de muller, "o símbolo da mocidade, na lediza da perfeizón e na saudade do adeus" (1982, p. 232).

5. "Hélia". O narrador sitúase na costa portuguesa e evoca o verso de Larsson na prosa de Vergílio Ferreira e, en particular, na súa personaxe Júlio Neves, quen se debate entre a realidade da súa esposa Helena e os soños e os desexos concentrados en Hélia, a que dá titulo a esta parte. O escritor Neves, rifado pola muller e a filla, vai perseguir sen éxito a Hélia (antes Helena) polo labirinto do tempo. Júlio imaxina a Hélia, posúea no areal da súa imaxinación porque Hélia-soño é a antítese de Helena-realidade. E porque o sol xa se puxo para o escritor que non sabe se aos cincuenta se é vello.

6. "A elegia de Marienbad". Agora o autor aludido é Goethe pero tamén o vello desta quenda, o Castelao desta quenda, o Neves desta quenda, o Larsson desta quenda, o Carvalho desta quenda. Sempre Abisag. A moza Ulrike (von Levetzow) trata o autor da "Elegía de Marienbad" de "cabaleiro ancián" de quen se explicitan moitas amadas na vida literaria (Gretchen, Bettina, Helena de Troia, Ulrike, Mignon) e na non literaria (Kätchen, as dúas Friederike, as dúas Charlotte, Cristiane, Marianne). Pero seguimos en Aos amores seródios. Lémbranolo o narrador que identifica a cabeza de mármore achada nun outeiro de Xonia coa brancura da 
nacida de Leda e o cisne Zeus e cando lle espeta ao patrucio que é Goethe: "Mais os vellos non deben de namorar-se".

7. "Fin de viage". O narrador evoca a última cea mantida no hotel polos arqueólogos que descubriron a cabeza de mármore hai corenta ou cincuenta anos. En realidade participan na cea seis persoas: o narrador, que era aos seus vinte anos o secretario do equipo e un dobre aprendiz de filólogo e de home; as dúas mulleres dos arqueólogos, que non cumpriran trinta anos; os seus maridos, o poeta Erik Larsson e o mestre arqueólogo de 70 anos, dúas veces divorciado e que aquí é irremediabelmente non só o mestre e o profesor senón o vello. As dúas mulleres, para o secretario do equipo (e tamén narrador), parécense á deusa marmórea e como raíñas helenísticas son Cleopatra e Berenice. As mulleres enféitanse, se cadra para o vello mestre, porque o poeta e o aprendiz de filólogo fican descartados e porque dos seus maridos xa non agardan novidades. $O$ narrador, aprendiz de home, mesmo contempla un intercambio de parellas. $\mathrm{O}$ vello mestre brinda cara ás copas que as mozas sosteñen cos seus brazos nus. $\mathrm{O}$ vello mestre non brinda cos catro homes. E para as mozas tampouco existe máis ca o vello. E ao brindar este pronuncia as palabras máxicas: "aos amores seródios". Elas rin felices e musicais, excitadas, embriagadas, fermosas. Tamén rin os maridos. E como remate total e definitivo, a referencia a Cleopatra e Berenice e a incorporación do verso de Villon: "Mais où sont les neiges d'antan?" (1984, p. 163) coa súa decidida invocación das neves de antano, do ubi sunt e das mulleres célebres da historia e da mitoloxía, algunhas inseridas polo noso autor neste brillante texto.

\subsection{Dos "Provérbios otomanos"}

En 1985 Carvalho Calero publica baixo o pseudónimo de Namiq Zyyá Provérbios otomanos: De Selim a Solimám. O breve relato conta en terceira persoa como no século XVI, no terceiro ano do reinado de Selim I, sultán dos turcos otomanos e Comendador dos Crentes, entrara no seu harén como cativa cristiá unha adolescente xeorxiana, dona á vez de "encantos arrebatadores" e de notábel influencia política no sultán. A xeorxiana convértese ao islam. Esa muller acaba representando unha "proteica capacidade de adaptaçom" (1985, p. 476) e unha probada fidelidade aos seus señores "fossem as que fossem as circunstáncias" (1985, p. 476). Os damnificados pola Bela Xeorxiana agardan mellor momento na súa vida coa morte de Selim e a proclamación califal do seu fillo Solimám. As mudanzas agardadas non se producen, o Grande Visir é confirmado no seu cargo e tamén os colaboradores do anterior Sultán. Solimám fica engaiolado polos saberes políticos da Bela Xeorxiana, quen mantén o seu poder e o seu status así como os seus ministros de confianza. A Bela Xeorxiana pasara do pacifismo de Selim ao 
belicismo de Solimám, pois "era capaz de pôr a sua técnica ao serviço das políticas mais dispares" (1985, p. 476). O narrador apela á crenza dunha posíbel morte do "brilhante cometa" (1985, p. 476) por volta de 1550 cando emerxe unha nova figura feminina: a de Roxelana. Pero a figura da Bela Xeorxiana ficou na historia consagrada coa expresión "De Selim a Solimám".

O autor evoca así sultanatos coñecidos na historia otomana, o de Selin I, sultán entre 1515 e 1520, quen establece a capital en Istambul, e a do seu fillo Solimán I, que ocupa o poder entre 1520 e 1566. Roxelana, referida no texto de Carvalho, logrou casar con Solimán converténdose na nai do próximo sultán Selin II. Era unha escrava ucraína, cristiá e comprada para o harén do sultán. Ao parecer a esposa principal era ministra e figura moi influente na vida política até o punto de levar o harén (constituído por mulleres xeorxianas e doutras nacionalidades) ao mesmo Palacio de Topkapi.

\section{SCÓRPIO E AS MULLERES}

Scórpio é unha das obras de Carvalho máis celebradas pola crítica literaria, tanto pola súa orixinalidade técnica e polas súas achegas estilísticas como por servir de reflexión e memoria individual e colectiva para o período 1910-1939, nunha interacción premeditada entre ficción e memoria e nunha meditación sobre a guerra e as súas consecuencias para a xeración de Carvalho e para os seus ideais.

Organizada en dúas partes de 77 e 59 capítulos, cada un comeza coa identificación da voz narradora. Entre elas mestúranse parentes (Aurélia, Francisco, Mercedes, Francisco), compañeiros (Sagitário, o contraste e complemento do protagonista, Salgueiro, empeñado en escribir a narración longa Scórpio semellante á que lemos e voz que ten moito do autor, Casado, Barreiro) e as mulleres de Scórpio. Algúns narradores son anónimos.

No romance aparecen espazos que acollen a biografía de Scórpio. Ferrol, onde nace de pai descoñecido e cuxa nai morre aos poucos días de el nacer, sendo criado e adoptado por Aurélia e Francisco, pais xa de catro fillos.

A Compostela universitaria do Seminario de Estudos Galegos, a FUE e o Partido Galeguista, onde Rafael/Scórpio e Jorge Bermúdez "Sagitário" van estudar dereito e cultivar a literatura e o amor. A Salamanca dos estudos filolóxicos. Na segunda parte, Rafael acode a Madrid en xullo de 1936 para opositar a profesor de secundaria e estala a guerra. Xunto aos seus amigos Barreiro e Casado, mortos na guerra, convértese en miliciano republicano e despois en tenente, formado nunha escola militar de Valencia e destinado a Úbeda, na fronte andaluza. Mentres a súa esposa e filla viven en Ferrol, Scórpio atopa a morte en Barcelona aos 27 anos nun bombardeo da aviación fascista. 
Esa riqueza e pluralidade de voces narradoras, a axilidade do relato, a contradición entre as luces e as sombras que acompañan o protagonista mudo, a honestidade con que viaxamos ao pasado e a presenza de figuras femininas son elementos determinantes. Rafael resulta un ser excepcional que cativa a mulleres e colegas, un ser misterioso, silente e enigmático.

A vida sentimental de Rafael e as paixóns que desata están penetradas de contradición e tensión, como se pode comprobar na súa ambigua relación con Chéli, con quen casa, Merche ou Amália, por non falarmos de Cleo, en cuxos brazos morre.

A narración indaga na vida das persoas e das cidades (Ferrol e Compostela); nos avatares económicos e afectivos; nas relacións sociais, nos hábitos; nos soños, ambicións e devezos dunha xeración que militou no galeguismo republicano e exerceu o oficio literario. Non é difícil reconstruír importantes segmentos da biografía de Carvalho Calero á beira de diversos acontecementos históricos como os ligados á República e á guerra civil ou a personaxes como Castelao, Bóveda, Suárez Picallo ou Quintanilla.

Scórpio ofrece moitas achegas ao universo do desexo, do erotismo e das relacións amorosas. A obra móstranos un amplo abano de realizacións que permiten entrever variadas solucións. É frecuente que o pracer se reduza a unha ilusión ou a un soño, que se impoñan as obrigas familiares e sociais sobre os sentimentos das persoas, que rexistremos casamentos por conveniencia, relacións fundamentadas no engano e nas convencións e personaxes que reprimen as súas verdadeiras paixóns.

Scórpio é un home alto e fermoso, louro e de ollos azuis que cativa as persoas que entran en contacto con el. Intelixente e brillante, móstrase con frecuencia enigmaticamente indiferente aos desexos que esperta nas mulleres. Centrado nos seus estudos de dereito e filosofía e letras e na escrita poética, indiferente á actividade política, nunca confirma nin desmente os moitos rumores que circulan sobre a súa activísima vida amorosa nin exhibe entusiasmo polas mulleres.

Excluídas as mulleres da súa familia (as súas tres nais, Antónia, Aurélia e Mercedes ou as súas irmás Socorro e Teresa), cada un dos espazos vitais do protagonista é o escenario para a súa relación con algunhas mulleres importantes na súa vida. En Ferrol, Chéli. En Compostela Cleo, Eugénia, Amália, Merche e Rosa. En Salamanca Helena ou Luzita. Scórpio esperta o interese no romance doutras mulleres: Mariña, que traballa na casa de Cleo e Eugenia, as amigas viguesas de Merche, as colegas de Salamanca Carmen e Luísa e mesmo Rosário, a parella do tenente Pascual. En Madrid, hai unha moza, Artemisa, que tamén oposita. Brillante, seria, fría, elegante, compite intelectualmente con Scórpio pero é das 
poucas mulleres que non coquetean con el. É como Scórpio en feminino, fermosa, intelixente e sobresaliente.

Cleo é unha das mulleres máis importantes na vida de Scórpio. Unha cubana rica e con moitos encantos, compañeira de estudos en Compostela que rompe a súa nacente relación co ferrolán ao coñecer a que Scórpio mantén coa súa irmá Eugenia, unha moza viúva, misteriosa e sedutora, que compite en beleza coa súa irmá.

Cleo esperta o interese de todos os seus compañeiros e, fronte ás súas compañeiras, é máis ousada e arriscada na súa relación co sexo oposto. É así que consegue beixar ao ferrolán. Casados os dous e transcorridos once anos, Cleo e Scórpio (capitán de cabalaría) reviven o seu amor cando se encontran durante a guerra en Paterna, onde o marido de Cleo exerce o cargo de xefe do Estado Maior. Vense intimamente en Barcelona onde os dous atopan a morte en 1938 durante un bombardeo da aviación fascista. Salgueiro vaise encargar de que non se saiba que os seus cadáveres apareceron xuntos.

A relación con Merche é unha relación de amor odio. Compañeira de estudos en Compostela, moi orgullosa e casada con Sagitário, é quen máis duramente critica a Scórpio, o seu dolorosísimo ben. Pero dalgunha maneira tamén o ama. Nas vésperas da voda de Scórpio e cando Merche xa está casada manteñen unha relación íntima e sexual.

A relación con Rosa é menos intensa. Está referida aos encontros e aos bailes no forno da Carricova, no que os mozos universitarios Scórpio, Sagitário e Salgueiro mocean con Rosa, Carminha e Luzia. Rosa é unha moza pobre, enferma e costureira. Estas relacións logo serán esquecidas, por moito que no corazón de Rosa agrome a súa especial vinculación con Scórpio.

Máis estraña é a relación que Scórpio mantén con Amália, a moderna e rompedora esposa do profesor Maluquer que gusta do flirt co discípulo predilecto do seu marido. Aburrida e casada sen amor cun sabio que non atende o seu fogo amoroso, Amália é unha muller irresistíbel e arrebatadora, que centra o seu flirt fantaseando co ferrolán. Afastados cando Maluquer é destinado a Madrid, volven encontrarse en Salamanca, onde Amália e Scórpio conseguen dispor dunhas horas de intimidade, e finalmente en Barcelona desde onde o profesor Maluquer notifica epistolarmente á viúva a morte de Scórpio.

En Salamanca hai dúas compañeiras de estudos interesadas en Scórpio. Helena, unha moza fermosa, intelixente e de boa familia que sabe xa con quen vai casar pero que devece por unha aventura co galego, indiferente a ese interese e ao de Luzita que o consegue beixar emocionada no final de curso, cando Scórpio abandona Salamanca de volta a Galiza.

Chéli é a muller que Scórpio ten máis a man. Criouse con ela. Inocente, anxelical, agochada, triste, escríbelle cartas abrindo o seu corazón. Chéli ámao sempre, 
illada en Ferrol e sen poder confirmar os rumores que circulan sobre Scórpio. Padece as ausencias de Scórpio en Compostela e Salamanca pero logra casar con el e facer felices aos pais de ambos. Cando Scórpio perde a vida, Chéli é nai dunha cativa, Aurélia.

Abreviaturas UtiLIZADAS

AS: Aos amores seródios

C: A cegoña

GB: A gente da Barreira

LC: O lar de Clara

PC: As pitas baixo a chúvia
S: Scórpio

SP: Os señores da Pena

SS: Provérbios otomanos: De Selim a Solimám

T: Os tumbos

\section{REFERENCIAS BIBLIOGRÁFICAS}

\section{Obra narrativa de Carvalho Calero}

Carvalho Calero, Ricardo (1950). Os tumbos. Alba. Verso y prosa, 5, [s.p.].

Carvalho Calero, Ricardo (1951). A xente da Barreira. Santiago de Compostela: Bibliófilos Gallegos.

Carvalho Calero, Ricardo (1952). As pitas baixo a choiva. Lar, 224-225, 35-64.

Carvalho Calero, Ricardo (1957). A cigoña. Vida Gallega, 729, 12 e 16.

Carvalho Calero, Ricardo (1979). Aos amores seródios. Grial, 63, 81-88.

Carvalho Calero, Ricardo (1982). A gente da Barreira e outras histórias. Santiago de Compostela: Follas Novas.

Carvalho Calero, Ricardo (1984). Narrativa completa. Sada: Ediciós do Castro.

Carvalho Calero, Ricardo (1985). Provérbios otomanos: De Selim a Solimám. Agália, 4, 475-476.

Carvalho Calero, Ricardo (1987). Scórpio. Santiago de Compostela: Sotelo Blanco. Carvalho Calero, Ricardo (1997). A gente da Barreira. Vigo: Asociación Socio-Pedagóxica Galega. Ed. de M. Pilar García Negro.

Carvalho Calero, Ricardo (1997). Scórpio. Vigo: Asociación Socio-Pedagóxica Galega.

Carvalho Calero, Ricardo (2002). A xente da Barreira. A Coruña: La Voz de Galicia. Carvalho Calero, Ricardo (2008). As pitas baixo a choiva. Ferrol: Embora.

Carvalho Calero, Ricardo (2017). Scórpio. Santiago: Através Editora. Epílogo de Arturo Casas.

Carvalho Calero, Ricardo (2020). A xente da Barreira. Vigo: Galaxia. 
Sobre A narrativa de Carvalho Calero

Blanco García, Carmen (2020). Testemuña fraternal: Sabe S., Salgueiro, Sagitário, Scórpio. Tempos Novos, 276, 80-82.

Casas Vales, Arturo (2002). A descrición na obra narrativa de Carvalho Calero: análise retórica e hermenéutica. En: Teresa López e Francisco Salinas, eds. Actas do Simposio Ricardo Carvalho Calero "Memoria do Século". A Coruña: Universidade da Coruña/ Asociación Sócio-Pedagóxica Galega, 119-135.

Delgado Corral, Concepción (1989). Salgueiro: A voz de um autor de ficçom. Agália, 19, 331-342.

Delgado Corral, Concepción (2000). O proxecto de facer un romance e o tempo da escrita dramáticamente vivido. En José L. Rodríguez, ed. Estudos dedicados a Ricardo Carvalho Calero. Santiago de Compostela: Parlamento de Galicia/ Universidade de Santiago de Compostela, vol. I, 141-153.

Dobarro Paz, Xosé M. (2002). A primeira novela da posguerra. En: Crítica e autores: artigos e entrevistas publicados en La Voz de Galicia. A Coruña: La Voz de Galicia, 116-117.

Forcadela, Manuel (2002). A narrativa de Carvalho Calero na encrucillada dos anos cincuenta. En: Teresa López e Francisco Salinas, eds. Actas do Simposio Ricardo Carvalho Calero "Memoria do Século". A Coruña: Universidade da Coruña/ Asociación Sócio-Pedagóxica Galega, 109-117.

García Negro, M. Pilar (1982). Unha leitura de A xente da Barreira. En: Homenaxe a Carballo Calero. A Coruña: Sociedade Cultural Medulio, 37-40.

Herrero Figueroa, Araceli (1983). Sobre A xente da Barreira: breve aproximación á leitura dunha novela. Grial, 81, 368-376.

Herrero Figueroa, Araceli (1992). O estatuto do narrador: pluridiscursividade e intertextualidade em Aos amores seródios. En M. Carmo Henríquez Salido, ed. Actas III Congresso Internacional de Língua Galego-Portuguesa na Galiza. A Corunha: AGAL, 569-581.

López Silva, Inma (2001). Pactos de lectura e conciencia histórica en Scórpio. Ferrol análisis, 16, 126-131.

Marco, Aurora (2002). Criar prosa en galego. En: Crítica e autores: artigos e entrevistas publicados en La Voz de Galicia. A Coruña: La Voz de Galicia, 117-118.

Martínez Pereiro, Carlos P. (1991). Scórpio ou a moi intelixente caza-cruzada dun fantasma. A Nosa Terra. A nosa cultura, 13, 71-76.

Martínez Pereiro, Carlos P. (2002). Do carácter híbrido na narrativa breve de Carvalho Calero: da ambigua verdade intempestiva de Aos amores seródios. En: Teresa López e Francisco Salinas, eds. Actas do Simposio Ricardo Carvalho Calero "Memoria do Século". A Coruña: Universidade da Coruña/ Asociación Sócio-Pedagóxica Galega, 137-160. 
Martínez Teixeiro, Alva (2012). O carácter híbrido do discurso histórico-ficcional identitario en Scórpio de Ricardo Carvalho Calero. En: Olivia Rodríguez González, Laura Carballo Piñeiro e Burghard Baltrusch, eds. Novas achegas ao estudo da cultura galega II [Recurso electrónico]: enfoques sociohistóricos e lingüístico-literarios / IX Congreso Asociación Internacional de Estudos Galegos. A Coruña: Universidade da Coruña, 267-278.

Montero Santalha, J.-Martinho (1993). Carvalho Calero e a súa obra. Santiago de Compostela: Laiovento.

Quiroga Díaz, J. Carlos (1987). Scórpio, história rosa e narrador polifónico. Agália, 12, 486-488.

Quiroga Díaz, J. Carlos (1992). Acerca do conjunto narrativo de Carvalho Calero: (parábola geométrica). En: M. Carmo Henríquez Salido, ed. Actas III Congresso Internacional de Lingua Galego-Portuguesa na Galiza. A Corunha: AGAL, 593-608.

Rabuñal, Henrique (2000). Carvalho Calero e o teatro. En José L. Rodríguez, ed. Estudos dedicados a Ricardo Carvalho Calero. Santiago de Compostela: Parlamento de Galicia/ Universidade de Santiago de Compostela, vol. I, 281-292.

Rabuñal, Henrique (2011). Achegamento urxente á narrativa de Carvalho Calero. En: Carlos C. Biscainho Fernandes e Xosé M. Sánchez Rei, coords. Ricardo Carvalho Calero: ciencia, literatura e nación. A Coruña: Universidade da Coruña, [157]-174.

Rabuñal, Henrique (2020). Ricardo Carvalho Calero. O anxo da terra. Vigo: Galaxia. Souto, Elvira (1990). Romulianos e sabinos (ou "O segredo de Rafael"). A Trabe de Ouro, 2, 231-246.

Souto, Elvira (1991). A viagem heróica: Scórpio. En: Viagens na Literatura. Santiago de Compostela: Laiovento, 69-105.

Vázquez Souza, Ernesto (1997). Unha leitura de Scórpio de Ricardo Carvalho Calero. Tese de licenciatura. Universidade da Coruña.

Villanueva, Darío (2000). Lectura de Scórpio. En José L. Rodríguez, ed. Estudos dedicados a Ricardo Carvalho Calero. Santiago de Compostela: Parlamento de Galicia/ Universidade de Santiago de Compostela, vol. I, 327-334.

Villanueva, Darío (2002). Carvalho Calero novelista. En: Teresa López e Francisco Salinas, eds. Actas do Simposio Ricardo Carvalho Calero "Memoria do Século". A Coruña: Universidade da Coruña/ Asociación Sócio-Pedagóxica Galega, 323. 339. 